\title{
Flaxseed lignan attenuates high-fat diet-induced fat accumulation and induces adiponectin expression in mice
}

\author{
S. Fukumitsu ${ }^{1}$, K. Aida ${ }^{1}$, N. Ueno ${ }^{1}$, S. Ozawa ${ }^{2}$, Y. Takahashi $^{3}$ and M. Kobori ${ }^{3 *}$ \\ ${ }^{1}$ Nippon Flour Mills Co. Ltd., Central Laboratory, 5-1-3 Midorigaoka, Atsugi, Kanagawa 243-0041, Japan \\ ${ }^{2}$ Rakuno Gakuen University, 582-1 Bunkyodai-Midorimuchi, Ebetsu, Hokkaido 069-8501, Japan \\ ${ }^{3}$ National Food Research Institute, 2-1-12, Kannondai, Tuskuba, Ibaraki 305-8642, Japan \\ (Received 11 September 2007 - Revised 16 November 2007 - Accepted 13 December 2007 - First published online 6 February 2008)
}

Flaxseed lignan secoisolariciresinol diglucoside (SDG) has been reported to prevent and alleviate lifestyle-related diseases including diabetes and hypercholesterolaemic atherosclerosis. This study assesses the effect of SDG on the development of diet-induced obesity in mice and the effect of the SDG metabolite enterodiol (END) on adipogenesis in 3T3-L1 adipocytes. We compared body weight, visceral fat weight, liver fat content, serum parameters, mRNA levels of lipid metabolism-related enzymes and adiponectin in mice fed either a low-fat diet (5\% TAG), high-fat diet $(30 \%$ TAG) or high-fat diet containing 0.5 and $1.0 \%(\mathrm{w} / \mathrm{w})$ SDG for 4 weeks. Administration of SDG to mice significantly reduced highfat diet-induced visceral and liver fat accumulation, hyperlipaemia, hypercholesterolaemia, hyperinsulinaemia and hyperleptinaemia. SDG also suppressed sterol regulatory element binding protein 1c mRNA level in the liver and induced increases in the adiponectin mRNA level in the white adipose tissue and carnitine palmitoyltransferase I mRNA level in the skeletal muscle. Differentiated 3T3-L1 adipocytes were treated with $0,5,10$ and $20 \mu \mathrm{mol} / 1 \mathrm{END}$ and then assayed for mRNA expression of adipogenesis-related genes and DNA binding activity of PPAR $\gamma$ to the PPAR response element consensus sequence. END induced adipogenesis-related gene mRNA expression including adiponectin, leptin, glucose transporter 4 and PPAR $\gamma$, and induced PPAR $\gamma$ DNA binding activity in 3T3-L1 adipocytes. In conclusion, SDG induced adiponectin mRNA expression and showed beneficial effects on lipid metabolism in diet-induced obesity in mice. Flaxseed lignans are suggested to regulate adipogenesis-related gene expressions through an increase in PPAR $\gamma$ DNA binding activity.

Flaxseed: Lignan: Obesity: Adiponectin

Obesity is a major risk factor for various diseases, and results from an imbalance between energy intake and expenditure. It is also known that altered lipid metabolism, including fat oxidation and fatty acid synthesis, is a related factor in obesity ${ }^{(1,2)}$. Furthermore, diet-induced obesity in man is often complicated by various lifestyle-related diseases, including diabetes, hyperlipaemia, hypertension and hyperinsulinaemia. Therefore, prevention of obesity is strongly encouraged in order to alleviate various lifestyle-related diseases.

Lignans are found in various foodstuffs, such as plant seeds, whole grains, legumes, vegetables and fruits ${ }^{(3)}$. Flax (Linum usitatissimum) is one of the richest sources of plant lignans ${ }^{(4)}$. The concentration of lignans in flaxseed was shown to be more than 100 times higher than that in most other foods ${ }^{(3)}$. Most of the flaxseed lignan is secoisolariciresinol diglucoside (SDG) which is present in a much higher proportion in the seed than in other tissues ${ }^{(3)}$. Flaxseeds are consumed daily as an ingredient in multigrain breads and topping for breads, bagels and muffins in Europe, Canada and the USA. They also contain $37 \%$ of their mass as oil of which $50 \%$ is $\alpha$-linolenic acid ( $n-3$ fatty acid) and have been the focus of interest in the field of food elements due to their potential health benefits $^{(5,6)}$. Flaxseed lignan SDG is converted by bacteria in the colon of man and other animals to the biologically active lignans, enterodiol (END) and enterolactone $(\mathrm{ENL})^{(7,8)}$. The structures of END and ENL are similar to oestradiol, an endogenous oestrogen. This structural similarity accounts for the ability of these compounds to bind to oestrogen receptors and exert weak oestrogenic or anti-oestrogenic effects, depending on the presence of stronger oestrogen ${ }^{(3)}$. They are suggested to protect and help against hormone-sensitive cancers such as those of the breast, endometrium and prostate ${ }^{(9)}$. Furthermore, SDG and the mammalian lignans END and ENL have anti-oxidant activity. The anti-oxidant activities of SDG, END and ENL were investigated by the ability to scavenge exogenously generated hydroxyl radical as measured by HPLC and the ability to prevent lipid peroxidation in liver homogenate ${ }^{(10)}$. In another work, SDG was claimed to be effective in reducing hypercholesterolaemic atherosclerosis by reducing oxidative stress ${ }^{(11)}$. Administration of SDG was reported to be effective in inhibiting the development of type 1 and type 2 diabetes and pulmonary metastasis of

Abbreviations: CPT-1, carnitine palmitoyltransferase I; DMEM, Dulbecco's modified Eagle's medium; END, enterodiol; ENL, enterolactone; PPRE, PPAR response element; SDG, secoisolariciresinol diglucoside; SREBP-1c, sterol regulatory element binding protein 1c.

* Corresponding author: Dr Masuko Kobori, fax +81 29838 7996, email kobori@affrc.go.jp 
melanoma cells ${ }^{(12-14)}$. These reports suggest that flaxseed lignans could be a potentially useful dietary source for the prevention and improvement of lifestyle-related diseases.

In the present study, we have examined the effects of the flaxseed lignan SDG on high-fat diet-induced obesity in C57BL/6 mice. We show that purified SDG improves highfat diet-induced visceral and liver fat accumulation, hypercholesterolaemia, hyperinsulinaemia and hyperleptinaemia.

Recent studies have shown that adipose tissue is not simply a store of excess energy, but also secretes a variety of hormones called adipocytokines, which are adipose-specific secretory factors ${ }^{(15)}$. Dysregulated secretion of adipocytokines also participates in the pathogenesis of lifestyle-related diseases $^{(16)}$. The adipocytokine adiponectin is believed to decrease TAG and to improve insulin resistance in obesity ${ }^{(17)}$. Here we demonstrate that flaxseed lignans induce the expression of adiponectin in white adipose tissue in dietinduced obesity in mice. Flaxseed lignans are suggested to regulate adipogenesis-related gene expression through an increase in PPAR $\gamma$ DNA binding activity.

\section{Materials and methods}

\section{Preparation of secoisolariciresinol diglucoside and enterodiol}

Lignan SDG was isolated from flaxseeds (Linum usitatissimum) using a modification of the methods of Johnsson et al. ${ }^{(18)}$. Briefly, flaxseeds were defatted with $n$-hexane. The defatted flaxseed flour was subjected to alkaline hydrolysis for $3 \mathrm{~h}$ under constant rotation using $0.4 \mathrm{~mol} / \mathrm{l}$ sodium hydroxide in aqueous methanol at $70^{\circ} \mathrm{C}$. Crude SDG was recovered after reversed-phase silica gel chromatography (DM1020T; Fuji Silysia Chemical Ltd, Kasugai, Aichi, Japan) of acidic extracts ( $\mathrm{pH} 3.0$ by the addition of phosphoric acid) by elution with $40 \%$ methanol. The filtrate was evaporated, and pure SDG was obtained by passing crude SDG through silica gel (BW-200; Fuji Silysia Chemical Ltd) and eluting with chloroform containing increasing amounts of methanol (10-30\%). The purity of SDG was confirmed by HPLC ${ }^{(18)}$ and time-offlight $\mathrm{MS}^{(19)}$. Isolated SDG was confirmed to have a purity of about $90 \%$ or more by these methods. END was purchased from Sigma Aldrich Japan (Sinagawa, Tokyo, Japan).

\section{Animals and diets}

Male C57BL/6 mice were purchased at 7 weeks of age (Japan SLC Inc., Hamamatsu, Shizuoka, Japan) and fed commercial pellets (MR stock; Nosan Corp., Yokohama, Kanagawa, Japan) for 1 week to stabilize their metabolic condition. The mice were divided into four groups ( $n 5$; two or three mice per cage) and were provided one of the four synthetic diets: a low-fat diet (containing $5 \%$ maize oil (w/w) as fat, $20 \%$ casein, $66.35 \%$ maize starch, $4 \%$ cellulose, $0.8 \%$ vitamin mixture (AIN-76), 3.5\% mineral mixture (AIN-76), 0.2\% choline bitartrate and $0.15 \%$ DL-methionine); a high-fat diet (containing $20 \%$ maize oil and $10 \%$ lard as fat, $20 \%$ casein, $28.35 \%$ maize starch, $13 \%$ glucose, $4 \%$ cellulose, $0.8 \%$ vitamin mixture (AIN-76), $3.5 \%$ mineral mixture (AIN-76), $0.2 \%$ choline bitartrate and $0.15 \%$ DL-methionine); or SDG diet consisting of the high-fat diet containing 0.5 or $1.0 \%$ SDG. Mice were maintained on these diets for 4 weeks. This experimental protocol was approved by the Ethical Committee of Nippon Flour Mills Company.

\section{Blood analysis}

At the conclusion of this experiment, mice were killed under anaesthesia and blood was collected from the heart immediately. The serum concentration of TAG, total cholesterol, glucose, glutamic oxaloacetic transaminase and glutamic pyruvic transaminase was measured enzymatically with commercial kits (Wako Pure Chemical Industries, Osaka, Japan). Serum insulin and leptin concentrations were measured using ELISA kits (Sibayagi Co., Sibukawa, Gunma, Japan and Morinaga Institute of Biological Science Inc., Yokohama, Kanagawa, Japan, respectively).

\section{Fat pad weights}

Two fat pads (epididymal and perirenal fat) were dissected from each animal and weighed, and then separately stored at $-20^{\circ} \mathrm{C}$ in RNAlater RNA Stabilization reagent (Qiagen KK, Tokyo, Japan).

\section{Measurement of faecal lipids}

Faeces were collected twice on a per-cage basis for $2 \mathrm{~d}$ after 3-4 weeks of feeding. After drying, faecal lipids were extracted and measured following the method of Folch et al. ${ }^{(20)}$.

\section{Measurement of liver TAG and total cholesterol}

The liver TAG and total cholesterol contents were extracted following the method of Folch et al. ${ }^{(20)}$ and measured using commercial enzyme kits (Wako Pure Chemical Industries).

\section{Quantitative real-time PCR analysis}

Total RNA was extracted from liver, adipose tissue, skeletal muscle and differentiated 3T3-L1 cells using Isogen reagent (Nippon Gene, Tokyo, Japan) according to the manufacturer's protocol. For quantitative real-time PCR, RNA was further purified using RNeasy (Qiagen). RNA (1 $\mu \mathrm{g})$ was reversetranscribed into cDNA using a ReverTra Ace $\alpha$ (Toyobo, Osaka, Japan). Then amplification was performed in a cDNA mixture on an ABI Prism 7000 Sequence Detector using SYBR Green Realtime PCR Master Mix (Toyobo), according to the manufacturer's protocol. Sequences of primers used for quantitative real-time PCR were as follows: sterol regulatory element binding protein 1c (SREBP-1c), $5^{\prime}$-atcggcggggaagctgtcggggtagcgtc- $3^{\prime}$ and $5^{\prime}$-actgtcttggttgttgatgagctggagcat- $3^{\prime}$; fatty acid synthase, $5^{\prime}$-ttccaagacgaaaatgatgc$3^{\prime}$ and $5^{\prime}$-attgtgggatcaggagagc- $3^{\prime} ;$ PPAR $\alpha, 5^{\prime}$-aggcagatgacetggaaagtc- $3^{\prime}$ and $5^{\prime}$-atgcgtgaactccgtagtgg- $3^{\prime}$; carnitine palmitoyltransferase I (CPT-1), 5'-cgcacggaaggaaaatgg- $3^{\prime}$ and $5^{\prime}$ tgtgcccaatattcctgg- $3^{\prime}$; acyl-CoA oxidase, $5^{\prime}$-cttgttcgcgcaagtgagg- $3^{\prime}$ and $5^{\prime}$-caggatccgactgtttacc- $3^{\prime}$; adiponectin, $5^{\prime}$-gatggcagagatggcactcc- $3^{\prime}$ and $5^{\prime}$-cttgccagtgctgccgtcat- $3^{\prime}$; leptin, $5^{\prime}$-ccgccaagcagagggtcac- $3^{\prime}$ and $5^{\prime}$-gcattcagggctaacatccaact$3^{\prime} ; \beta$-actin, $5^{\prime}$-aagagaggtatcctgaccct- $3^{\prime}$ and $5^{\prime}$-tacatggetggggtgttgaa- $3^{\prime}$; adipose fatty acid binding protein, $5^{\prime}$-tgatgectttgtgggaacct- $3^{\prime}$ and $5^{\prime}$-gcttgtcaccatctcgtttctct-3'; GLUT4, 
$5^{\prime}$-tcgtcattggcattctggttg- $3^{\prime}$ and $5^{\prime}$-agctcgttctactaagagcac- $3^{\prime} ;$ PPAR $\gamma$, $5^{\prime}$-ccagagtctgctgatctgcg- $3^{\prime}$ and $5^{\prime}$-gccacctctttgctctgctc- $3^{\prime}$; CCAAT/enhancer-binding protein $\alpha, 5^{\prime}$-caaagccaagaagtcggtggacaa- $3^{\prime}$ and $5^{\prime}$-tcattgtgactggtcaactccagc-3'; glyceraldehyde-3-phosphate dehydrogenase, $5^{\prime}$-cctggagaaacctgccaagtatg- $3^{\prime}$ and $5^{\prime}$-agagtgggagttgctgttgaagtc- $3^{\prime}$. The relative amount of each transcript was normalized to the amount of $\beta$-actin and glyceraldehyde-3-phosphate dehydrogenase transcript in the same cDNA.

\section{Cell culture and differentiation}

3T3-L1 preadipocytes were cultured and differentiated as described previously ${ }^{(21)}$. Briefly, cells were cultured in Dulbecco's modified Eagle's medium (DMEM) containing $10 \%$ fetal bovine serum until confluent; $2 \mathrm{~d}$ after reaching confluence (D0), they were stimulated to differentiate with DMEM containing $10 \%$ fetal bovine serum, $0.25 \mu \mathrm{mol} / 1$ dexamethasone and $0.5 \mathrm{mmol} / \mathrm{l}$ isobutylmethylxanthine for $2 \mathrm{~d}$ (D2). Then, the cells were incubated with DMEM containing $10 \%$ fetal bovine serum and $5 \mu \mathrm{g} / \mathrm{ml}$ insulin. After $2 \mathrm{~d}$ (D4), the medium was replaced with DMEM, and the medium was then changed every $2 \mathrm{~d}$ for $5 \mathrm{~d}$ (D9). After the cells had been differentiated into adipocytes, the cells were treated with END for $24 \mathrm{~h}$.

\section{Measurement of PPAR $\gamma$ DNA binding activity}

Nuclear extracts from 3T3-L1 cells were prepared using Nuclear Extract Kit (Active Motif, Tokyo, Japan). PPAR $\gamma$ binding to the PPAR response element (PPRE) consensus sequence was detected using a PPAR $\gamma$ Transcription Factor Assay Kit (Cayman Chemical Co., Ann Arbor, MI, USA).

\section{Statistical analysis}

Statistical analysis was performed using SPSS software (Chicago, IL, USA). The data are presented as means and their standard errors. Statistical significance was evaluated with ANOVA. Homogeneity of variances among groups was tested using Bartlett's test. Differences between groups were examined for statistical significance using Dunnett's test. A $P$ value of less than $0 \cdot 05$ was considered statistically significant.

\section{Results}

Effect of secoisolariciresinol diglucoside on body and visceral fat weight

Fig. 1 shows the body weight of mice for 4 weeks. A high-fat diet resulted in a significant increase in body weight compared with mice fed a low-fat diet. The average body weight of mice fed a high-fat diet containing 0.5 or $1.0 \%$ SDG increased less than that of mice fed a high-fat diet. Although the differences were not significant, the result was reproducible (data not shown). During the test period, the food intake was higher in mice fed a low-fat diet than in mice fed a high-fat diet, but was not significantly different between the high-fat and a high-fat containing 0.5 or $1.0 \%$ SDG diet groups (Table 1). The calculated energy intake was higher in mice fed a low-fat diet than in mice fed a high-fat diet (Table 1). A $1 \%$ SGD diet

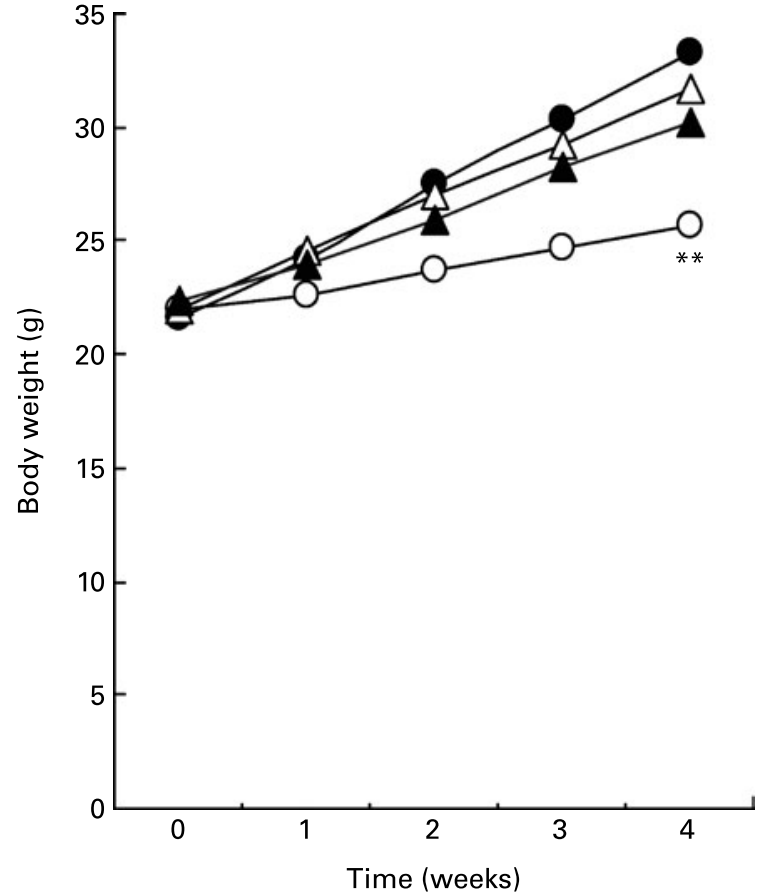

Fig. 1. Effect of secoisolariciresinol diglucoside (SDG) on body weight in mice fed different diets for 4 weeks $(O$, low-fat diet; $\bullet$, high-fat diet; $\triangle$, highfat diet $+0.5 \%$ SDG; $\boldsymbol{\Lambda}$, high-fat diet $+1.0 \%$ SDG). Values are means (five mice per group). Mean value was significantly different from those of the high-fat diet groups at the end of the experiment: ${ }^{\star *} P<0.01$.

reduced the energy intake in mice fed a high-fat diet. The visceral fat gain induced by a high-fat diet was significantly reduced in mice on the high-fat diet containing 0.5 or $1.0 \%$ SDG (Table 1).

Effect of secoisolariciresinol diglucoside on liver lipid levels

As shown in Table 1, a high-fat diet significantly increased the liver TAG content as compared to a low-fat diet. A high-fat diet containing $1.0 \%$ SDG significantly decreased the liver TAG content as compared to a high-fat diet (Table 1).

\section{Effect of secoisolariciresinol diglucoside on serum biochemical levels}

Table 2 shows the major serum biochemical parameters. A high-fat diet significantly increased serum TAG, total cholesterol, and insulin and leptin concentrations as compared to a low-fat diet. The result shows that a high-fat diet resulted in the development of hyperlipaemia, hypercholesterolaemia, hyperinsulinaemia and hyperleptinaemia. Administration of $1.0 \%$ SDG significantly reduced serum TAG, total cholesterol, and insulin and leptin concentrations as compared to a high-fat diet (Table 2).

Effect of secoisolariciresinol diglucoside on relative $m R N A$ expressions of lipid metabolism-related genes in the liver

We analysed the mRNA levels of lipid metabolism-related genes in the liver by quantitative real-time PCR. When compared to a high-fat diet alone, a high-fat diet containing 0.5 
Table 1. Effects of secoisolariciresinol diglucoside (SDG) on food and energy intake, liver lipid content and visceral fat weight in mice fed a high-fat diet†

(Mean values with their standard errors of five mice per group)

\begin{tabular}{|c|c|c|c|c|c|c|c|c|}
\hline & & & & & \multicolumn{4}{|c|}{ High-fat diet + SDG (\%) } \\
\hline & \multicolumn{2}{|c|}{ Low-fat diet } & \multicolumn{2}{|c|}{ High-fat diet } & \multicolumn{2}{|c|}{0.5} & \multicolumn{2}{|c|}{1.0} \\
\hline & Mean & SE & Mean & SE & Mean & SE & Mean & SE \\
\hline Food intake (g/mouse per $24 \mathrm{~h}$ ) & $4 \cdot 19^{\star \star}$ & 0.01 & $2 \cdot 63$ & 0.06 & $2 \cdot 52$ & 0.09 & $2 \cdot 43$ & 0.03 \\
\hline Energy intake (kJ/mouse per $24 \mathrm{~h})$ & $63 \cdot 5^{\star \star}$ & 2.0 & $55 \cdot 8$ & $1 \cdot 3$ & $53 \cdot 3$ & 1.9 & $51 \cdot 2^{*}$ & 0.5 \\
\hline Liver weight $(\mathrm{g})$ & $1 \cdot 10^{*}$ & 0.05 & 1.35 & 0.04 & 1.26 & 0.04 & 1.24 & 0.09 \\
\hline Liver TAG (mg/g liver) & $30 \cdot 7^{\star}$ & 0.8 & $49 \cdot 6$ & 1.8 & 46.5 & 4.8 & $36 \cdot 9^{*}$ & $2 \cdot 0$ \\
\hline Liver cholesterol (mg/g liver) & $11 \cdot 3$ & $1 \cdot 2$ & 9.9 & 0.2 & $10 \cdot 1$ & 0.3 & $8 \cdot 8$ & 0.5 \\
\hline Epididymal WAT $(\mathrm{g})$ & $1 \cdot 10^{\star}$ & 0.05 & 1.61 & $0 \cdot 11$ & $1 \cdot 22^{*}$ & 0.05 & $1.09^{*}$ & 0.15 \\
\hline Perirenal WAT $(\mathrm{g})$ & 0.15 & 0.04 & 0.29 & 0.06 & 0.27 & 0.04 & 0.19 & 0.04 \\
\hline
\end{tabular}

WAT, white adipose tissue.

Mean values were significantly different from those of the high-fat diet group: ${ }^{*} P<0.05,{ }^{* *} P<0.01$.

$\dagger$ The energy intake of mice over $24 \mathrm{~h}$ was measured on $2 \mathrm{~d} /$ week during the experimental period. Liver weight, lipid content and visceral fat weight were measured after 4 weeks of feeding.

and $1.0 \%$ SDG significantly reduced the mRNA level of the transcription factor SREBP-1c, which regulates lipid synthetic genes in the liver (Fig. 2 (a)). Although the differences were not statistically significant, the mRNA level of fatty acid synthase, which is one of the target factors of SREBP-1c, also tended to be lower in a high-fat diet containing 0.5 and $1.0 \%$ SDG than in a high-fat diet alone (Fig. 2 (a)). In contrast, differences in the mRNA expression levels of PPAR $\alpha$, CPT- 1 and acyl-CoA oxidase, which are $\beta$-oxidation-related genes, were not significant between these experimental groups (Fig. 2 (b)).

\section{Effect of secoisolariciresinol diglucoside on adiponectin} mRNA expression in white adipose tissue

We examined the mRNA levels of adiponectin, which are reduced by obesity, in white adipose tissue by quantitative real-time PCR. High-fat diets containing 0.5 and $1.0 \%$ SDG increased the mRNA level of adiponectin from 100 (SE11.3) to 166.5 (SE15.9) and 204.7 (SE31.8) \%, respectively. Thus, a high-fat diet containing $1.0 \%$ SDG significantly increased the mRNA level of adiponectin when compared to a highfat diet.
Effect of secoisolariciresinol diglucoside on relative $m R N A$ expressions of $\beta$-oxidation-related genes in skeletal muscle

Adiponectin shows acute and chronic effects on muscle metabolism by promoting $\beta$-oxidation ${ }^{(22)}$. We therefore analysed the mRNA levels of $\beta$-oxidation-related genes in the skeletal muscle by quantitative real-time PCR. A high-fat diet containing $1.0 \%$ SDG resulted in a significant increase in the mRNA level of CPT-1 compared to mice on a high-fat diet (Fig. 3). Although the differences in PPAR $\alpha$ mRNA levels were not statistically significant between mice fed high-fat and SDG diets, the average level of PPAR $\alpha$ mRNA was increased by the high-fat diet containing 0.5 or $1.0 \%$ SDG compared to the high-fat diet alone (Fig. 3). In contrast, the mRNA levels of acyl-CoA oxidase were not changed in mice fed a highfat diet and high-fat diets containing SDG (Fig. 3).

\section{Effects of enterodiol on adipogenesis in differentiated 3T3-L1 adipocytes}

To understand the mechanism of up-regulation of adiponectin expression by SDG we examined the effect of the SDG metabolite END on adipogenesis-related gene expression

Table 2. Effects of secoisolariciresinol diglucoside (SDG) on blood parameters in mice fed a high-fat diet (Mean values with their standard errors of five mice per group)

\begin{tabular}{|c|c|c|c|c|c|c|c|c|}
\hline & & & & & \multicolumn{4}{|c|}{ High-fat diet + SDG (\%) } \\
\hline & \multicolumn{2}{|c|}{ Low-fat diet } & \multicolumn{2}{|c|}{ High-fat diet } & \multicolumn{2}{|c|}{0.5} & \multicolumn{2}{|c|}{$1 \cdot 0$} \\
\hline & Mean & SE & Mean & SE & Mean & SE & Mean & SE \\
\hline TAG (mg/l) & $850^{*}$ & 49 & 1265 & 87 & 973 & 135 & $785^{\star}$ & 89 \\
\hline Total cholesterol (mg/l) & $1524^{\star *}$ & 62 & 2142 & 46 & 1959 & 94 & $1822^{*}$ & 18 \\
\hline Glucose (mg/l) & 1869 & 87 & 2393 & 192 & 2384 & 79 & 1994 & 103 \\
\hline Insulin (ng/ml) & $1.95^{\star \star}$ & 0.32 & $4 \cdot 70$ & 0.61 & 3.06 & 0.57 & $2 \cdot 52^{\star *}$ & 0.34 \\
\hline Leptin (ng/ml) & $3 \cdot 94^{\star \star}$ & 0.29 & $15 \cdot 70$ & 2.03 & $11 \cdot 62$ & 0.66 & $9 \cdot 17^{\star \star}$ & $1 \cdot 28$ \\
\hline GOT (IU/I) & $47 \cdot 1$ & $12 \cdot 0$ & $34 \cdot 2$ & $7 \cdot 9$ & 38.5 & 4.4 & $34 \cdot 8$ & 1.0 \\
\hline GPT (IU/I) & $10 \cdot 2$ & 0.9 & 9.7 & 0.5 & $10 \cdot 0$ & 1.7 & 8.5 & 1.8 \\
\hline
\end{tabular}

GOT, glutamic oxaloacetic transaminase; GPT, glutamic pyruvic transaminase.

Mean values were significantly different from those of the high-fat diet group: ${ }^{\star} P<0.05,{ }^{\star \star} P<0.01$. 

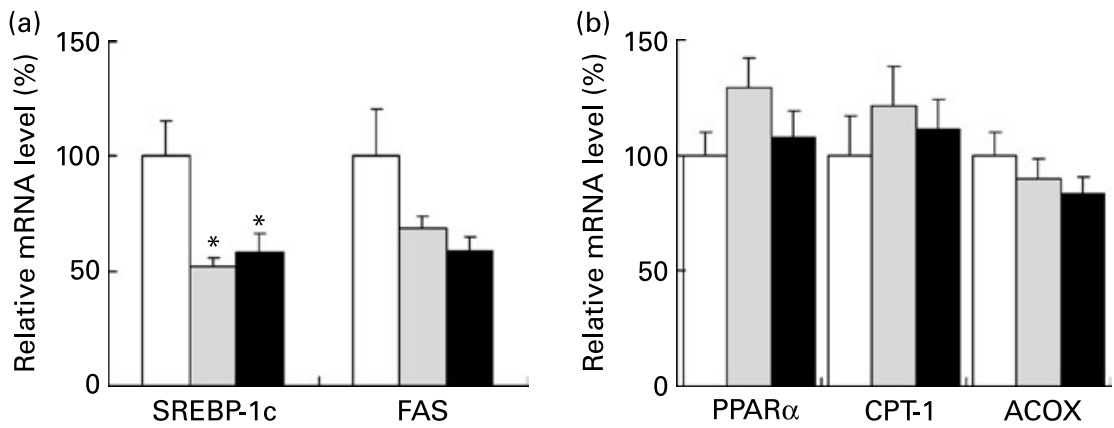

Fig. 2. Effect of secoisolariciresinol diglucoside (SDG) on mRNA levels of lipid metabolism-related genes in the liver of mice fed different diets for 4 weeks ( $\square$, high-fat diet; $\square$, high-fat diet $+0.5 \%$ SDG; $\mathbf{\square}$, high-fat diet $+1.0 \%$ SDG). Shown are the amounts of mRNA of sterol regulatory element binding protein $1 \mathrm{c}$ (SREBP-1c) and fatty acid synthase (FAS) (fatty acid synthetic genes) (a) and PPAR $\alpha$, carnitine palmitoyltransferase I (CPT-1) and acyl-CoA oxidase (ACOX) (fatty acid oxidation genes) (b). Relative mRNA levels were quantified by real-time PCR as described in the Materials and methods. The mRNA values are normalized to $\beta$-actin content. Values are means with their standard errors depicted by vertical bars (five mice per group). Mean values were significantly different from those of the high-fat diet group: ${ }^{\star} P<0.05$.

in differentiated 3T3-L1 adipocytes. 3T3-L1 adipocytes were treated with different concentrations of END $(0,5,10$ and $20 \mu \mathrm{mol} / \mathrm{l}$ ) for $24 \mathrm{~h}$. As shown in Fig. 4, END significantly increased the levels of mRNA of the adipogenesis-related genes adiponectin, GLUT4, leptin and PPAR $\gamma$.

\section{Effects of enterodiol on PPAR $\gamma$ DNA binding activity} in differentiated 3T3-L1 adipocytes

Activation of PPAR $\gamma$ involves ligand-specific conformational changes that recruit coactivators or corepressors. These protein-protein interactions lead to PPAR $\gamma$ heterodimerization with retinoid $X$ receptor. This complex then binds to the specific PPRE within the promoters of PPAR $y$ target genes, including adiponectin, leptin and GLUT4 ${ }^{(23-27)}$. We determined the effect of END on PPAR $\gamma$ DNA binding activity in differentiated 3T3-L1 adipocytes using a PPAR $\gamma$ Transcription Factor Assay Kit. As shown in Fig. 5, END significantly

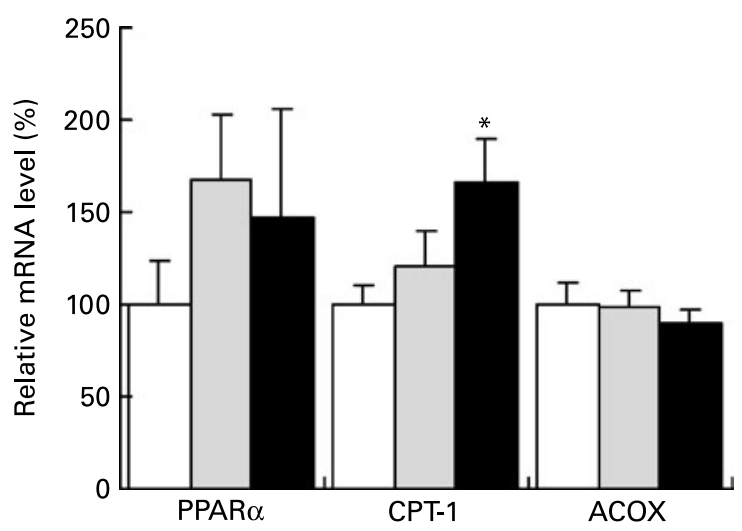

Fig. 3. Effect of secoisolariciresinol diglucoside (SDG) on mRNA levels of lipid metabolism-related genes in the skeletal muscle of mice fed different diets for 4 weeks ( $\square$, high-fat diet; $\square$, high-fat diet $+0.5 \%$ SDG; $\mathbf{\square}$, high-fat diet $+1.0 \%$ SDG). Shown are the amounts of mRNA of PPAR $\alpha$, carnitine palmitoyltransferase I (CPT-1) and acyl-CoA oxidase (ACOX) (fatty acid oxidation genes). Relative mRNA levels were quantified by real-time PCR. The mRNA values are normalized to $\beta$-actin content. Values are means with their standard errors depicted by vertical bars (five mice per group). Mean values were significantly different from those of the high-fat diet group: ${ }^{\star} P<0.05$. enhanced the PPAR $\gamma$ DNA binding activity in a dose-dependent manner.

\section{Discussion}

In the present study, we measured the effects of dietary-supplied flaxseed lignan (SDG) on the development of dietinduced obesity in C57BL/6 mice. Flaxseed has been reported to lower human serum total cholesterol and $\mathrm{TAG}^{(28,29)}$. A flaxseed meal was reported to lower plasma TAG and total cholesterol and hepatic fat deposition in lean and obese rats ${ }^{(30)}$. The flaxseed lignan SDG was shown to reduce the serum cholesterol level and suppress hypercholesterolaemic atherosclerosis ${ }^{(11)}$. Here, we demonstrate that SDG reduced high-fat diet-induced visceral and liver fat accumulation, hyperlipaemia, hypercholesterolaemia, hyperinsulinaemia and hyperleptinaemia in mice. Although SDG did not significantly reduce the high-fat diet-induced body weight gain, the present results show that SDG is effective in reducing diet-induced obesity in mice. SGD at $1 \%$ did not significantly reduce the food intake in mice fed a high-fat diet, but significantly reduced the calculated energy intake. The suppression of energy intake may partly contribute to the suppressive effect of SDG on highfat diet-induced fat accumulation and hyperlipaemia.

Sterol regulatory element binding proteins are important transcription factors that regulate fatty acid and cholesterol metabolism in the liver. SREBP-1c in particular plays a crucial role in the dietary regulation of most hepatic lipogenic genes. A previous report demonstrated that genes involved in fatty acid and TAG synthesis that are regulated by sterol regulatory element binding proteins include fatty acid synthase $^{(31)}$. In the present study, 1.0\% SDG significantly reduced the high-fat diet-induced serum TAG, cholesterol and liver TAG levels. We also observed that a high-fat diet containing 0.5 or $1.0 \%$ SDG resulted in a significant reduction in the mRNA levels of SREBP-1c in the liver compared to animals on a high-fat diet alone. The present findings suggest that the anti-obesity effects of dietary SDG are due to the suppression of genes involved in fatty acid and TAG synthesis through the regulatory activity of SREBP-1c.

The adipocytokine adiponectin has been shown to influence glucose and lipid homeostasis and insulin sensitivity. 


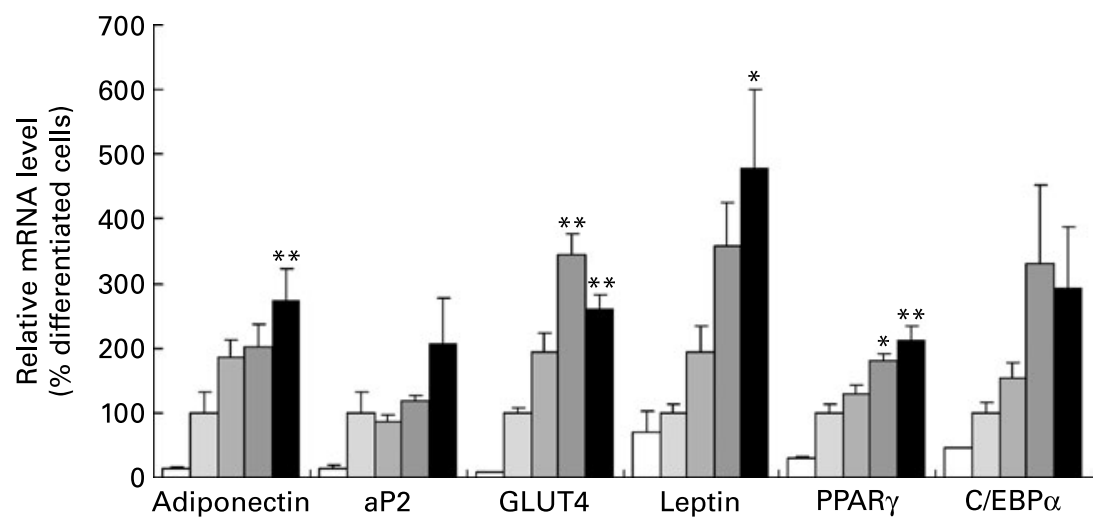

Fig. 4. Effect of enterodiol (END) on adipogenesis in differentiated 3T3-L1 cells. Cells were incubated for $24 \mathrm{~h}$ with END at 5 ( $\square$ ), 10 ( $\square$ ) and 20 ( $\square$ ) $\mu \mathrm{mol} / \mathrm{I}(\square$, differentiated cells + dimethyl sulphoxide; $\square$, undifferentiated cells + dimethyl sulphoxide). Relative mRNA levels were quantified by real-time PCR. The mRNA values are normalized to glyceraldehyde-3-phosphate dehydrogenase content. Values are means with their standard errors depicted by vertical bars of triplicate cultures. Mean values were significantly different from those of the differentiated cells group (no END): ${ }^{\star} P<0.05$, ${ }^{\star \star} P<0.01$. aP2, adipose fatty acid binding

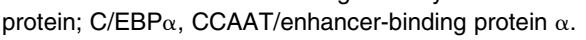

Adiponectin is expressed exclusively in the adipose tissue and is at lower levels in human and rodent models of obesity and type 2 diabetes ${ }^{(17)}$. Furthermore, obesity-related decreases in plasma adiponectin levels have been reported in man and experimental animals and hypoadiponectinaemia is closely related to insulin resistance $^{(32)}$. Expression of adiponectin has been shown to improve insulin resistance by decreasing TAG content in muscle and liver in obese mice ${ }^{(17)}$. Thus, increased adiponectin levels are strongly correlated with prevention of lifestyle-related diseases. In the present study, although significant differences were not detected in serum adiponectin levels in mice fed low-fat, high-fat and SDG diets, the mRNA level of adiponectin in white adipose tissue was significantly increased by SDG administration. Therefore, SDG in flaxseeds is likely to be useful as a food that can regulate adiponectin, and which can prevent or improve lifestyle-related diseases including obesity. In fact, feeding SDG has been reported to prevent lifestyle-related diseases including diabetes and arteriosclerosis ${ }^{(11,13)}$.

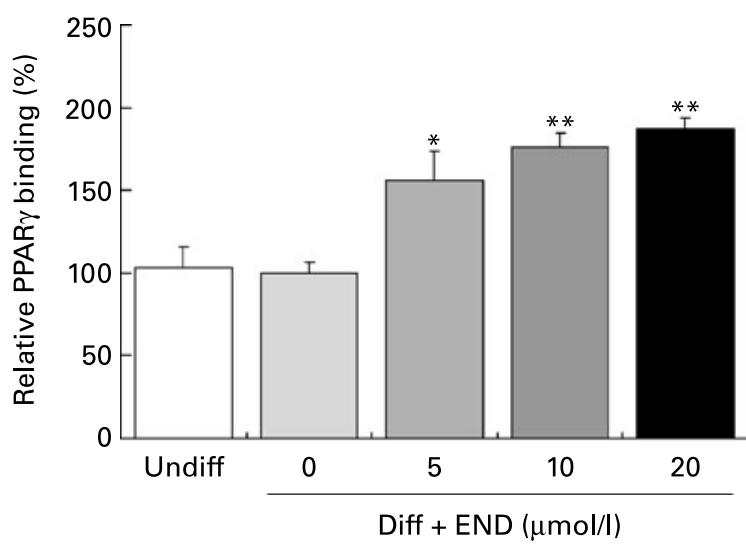

Fig. 5. Effect of enterodiol (END) on PPAR $\gamma$ binding activity in differentiated 3T3-L1 cells. Cells were incubated with END at 5, 10 and $20 \mu \mathrm{mol} / \mathrm{l}$ for $24 \mathrm{~h}$. DNA binding activity was determined using a PPARy Transcription Factor Assay Kit (ELISA) using nuclear extracts of 3T3-L1 cells. Values are means with their standard errors depicted by vertical bars of triplicate cultures. Mean values were significantly different from those of the differentiated cells group (no END): ${ }^{*} P<0.05,{ }^{* \star} P<0.01$. Diff, differentiated cells; Undiff, undifferentiated cells.
CPT-1, located on the mitochondrial outer membrane, is a molecule involved in the initial, regulated step in $\beta$-oxidation of fatty acids. It was previously reported that CPT- 1 mediates the transfer of the acyl-chain of the cytosolic long-chain acylCoA to carnitine ${ }^{(33)}$. Adiponectin in white adipose tissue is known to promote $\beta$-oxidation in the skeletal muscle ${ }^{(22)}$. In the present study, a high-fat diet containing $1.0 \%$ SDG significantly increased the mRNA level of CPT-1 in the skeletal muscle compared to a high-fat diet alone. The result suggests that SDG increases fat oxidation in the skeletal muscle by induction of CPT-1 expression. SDG may contribute to the enhancement of fat oxidation in the skeletal muscle through the beneficial effects of adiponectin.

Adiponectin and leptin have been demonstrated to increase rates of fatty acid oxidation and are likely to be the mechanism underlying their insulin-sensitizing effects ${ }^{(22)}$. GLUT4 is expressed in the insulin target tissue adipose, where it mediates an increase in glucose uptake and enhanced insulin sensitivity ${ }^{(23)}$. In addition, PPAR $\gamma$ is one of the key transcription factors that regulate adipogenesis and glucose and lipid metab$\mathrm{olism}^{(34)}$. PPAR $\gamma$ regulates the expressions of adiponectin, leptin and GLUT4. SDG was reported to be metabolized to the mammalian lignans END and ENL by bacterial flora in the colon which show enhanced biological activities ${ }^{(7,8,35)}$. Therefore, END and ENL but not SGD should mainly affect tissues after the consumption of SDG. We examined the effect of END and ENL on adipogenesis in differentiated 3T3-L1 adipocytes. In the present study, END significantly increased adiponectin, leptin, GLUT4 and PPAR $\gamma$ mRNA expression in differentiated 3T3-L1 adipocytes. END induced PPAR $\gamma$ binding to PPRE in a dose-dependent manner. In contrast, ENL significantly induced GLUT4 mRNA expression in differentiated 3T3-L1 cells at concentrations of 5, 10 and $20 \mu \mathrm{mol} / 1$ (data not shown). However, $5 \mu \mathrm{mol} / \mathrm{l}$ but not 10 or $20 \mu \mathrm{mol} / 1 \mathrm{ENL}$ significantly induced adiponectin, leptin, PPAR $\gamma$ and CCAAT/enhancer-binding protein $\alpha$ mRNA expression in 3T3-L1 adipocytes (data not shown). Moreover, 5 and $10 \mu \mathrm{mol} / \mathrm{l}$ but not $20 \mu \mathrm{mol} / \mathrm{l}$ ENL significantly induced PPAR $\gamma$ DNA binding activity in 3T3-L1 adipocytes (data not shown). The present results are reproducible and the disappearance of the effects of ENL at higher concentrations on adipogenesis-related gene expression and PPAR $\gamma$ DNA 
binding activity are under investigation. The present findings suggest that flaxseed lignans act as a PPAR $\gamma$ agonist and regulate the expression of adipogenesis-related genes, including adiponectin, leptin and GLUT4, through a PPRE-dependent mechanism in adipocytes. Previous studies demonstrated that the antidiabetic thiazolidinedione agents, troglitazone and rosiglitazone, were selective ligands for PPAR $\gamma$ and transcriptionally regulate adipogenesis-related genes containing the consensus PPRE ${ }^{(23-25,36)}$. Thus, flaxseed lignans as well as thiazolidinedione agents show an antidiabetic effect through PPAR $\gamma$-induced gene expression.

In summary, we have shown that the flaxseed lignan SDG beneficially affected high-fat diet-induced obesity in mice. SDG reduced high-fat diet-induced visceral and liver fat accumulation, and improved hyperlipaemia, hypercholesterolaemia, hyperinsulinaemia and hyperleptinaemia. In the liver, the mRNA level of the fatty acid synthesis-related gene SREBP-1c was significantly reduced by high-fat diets containing SDG. Increases in mRNA levels of adiponectin in white adipose tissue and CPT-1 in the skeletal muscle were significantly induced by $1.0 \%$ SDG. The present results suggest that SDG administration reduces fatty acid synthesis by suppressing SREBP-1c expression in liver and promotes $\beta$-oxidation in muscle by inducing adiponectin expression. Induction of adiponectin may also improve hyperinsulinaemia. Furthermore, we show that the SDG metabolite END induced the expression of adiponectin and other PPAR $\gamma$-regulated genes in differentiated 3T3-L1 adipocytes. END is likely to transcriptionally regulate adipogenesis-related genes, including adiponectin, leptin and GLUT4 in vivo.

These effects may prevent or improve obesity and may reduce the risk of lifestyle-related diseases, including diabetes, atherosclerosis and hypertension. Flaxseeds, which also contain PUFA and dietary fibre, are therefore a promising food to help decrease the risk of lifestyle-related diseases.

\section{Acknowledgements}

We thank all members of the Kobori laboratory for helpful discussions and comments. S. F. conducted most of the experiments. K. A., N. U. and S. O. worked on the animal studies. Y. T. worked on the gene expression analysis. M. K. supervised the study and wrote the manuscript. The authors state no conflicts of interest.

\section{References}

1. Pagliassotti MJ, Gayles EC \& Hill JO (1997) Fat and energy balance. Ann N Y Acad Sci 827, 431-448.

2. Triscari J, Nauss-Karol C, Levin BE \& Sullivan AC (1985) Changes in lipid metabolism in diet-induced obesity. Metabolism 34, 580-587.

3. Bhathena SJ \& Velasquez MT (2002) Beneficial role of dietary phytoestrogens in obesity and diabetes. Am J Clin Nutr 76, 1191-1201

4. Thompson LU, Rickard SE, Cheung F, Kenaschuk EO \& Obermeyer WR (1997) Variability in anticancer lignan levels in flaxseed. Nutr Cancer 27, 26-30.

5. Cunnane SC, Ganguli S, Menard C, et al. (1993) High alphalinolenic acid flaxseed (Linum usitatissimum): some nutritional properties in humans. Br J Nutr 69, 443-453.

6. Romans JR, Johnson RC, Wulf DM, Libal GW \& Costello WJ (1995) Effects of ground flaxseed in swine diets on pig performance and on physical and sensory characteristics and omega-3 fatty acid content of pork: I. Dietary level of flaxseed. J Anim Sci 73, 1982-1986.

7. Axelson M, Sjovall J, Gustafsson BE \& Setchell KD (1982) Origin of lignans in mammals and identification of a precursor from plants. Nature 298, 659-660.

8. Nesbitt PD, Lam Y \& Thompson LU (1999) Human metabolism of mammalian lignan precursors in raw and processed flaxseed. Am J Clin Nutr 69, 549-555.

9. Wang L, Chen J \& Thompson LU (2005) The inhibitory effect of flaxseed on the growth and metastasis of estrogen receptor negative human breast cancer xenografts is attributed to both its lignan and oil components. Int J Cancer 116, 793-798.

10. Prasad K (1997) Hydroxyl radical-scavenging property of secoisolariciresinol diglucoside (SDG) isolated from flax-seed. Mol Cell Biochem 168, 117-123.

11. Prasad K (1999) Reduction of serum cholesterol and hypercholesterolemic atherosclerosis in rabbits by secoisolariciresinol diglucoside isolated from flaxseed. Circulation 99, 1355-1362.

12. Li D, Yee JA, Thompson LU \& Yan L (1999) Dietary supplementation with secoisolariciresinol diglycoside (SDG) reduces experimental metastasis of melanoma cells in mice. Cancer Lett 142, 91-96.

13. Prasad K (2001) Secoisolariciresinol diglucoside from flaxseed delays the development of type 2 diabetes in Zucker rat. $J$ Lab Clin Med 138, 32-39.

14. Prasad K, Mantha SV, Muir AD \& Westcott ND (2000) Protective effect of secoisolariciresinol diglucoside against streptozotocin-induced diabetes and its mechanism. Mol Cell Biochem 206, 141-149.

15. Hu E, Liang P \& Spiegelman BM (1996) AdipoQ is a novel adipose-specific gene dysregulated in obesity. J Biol Chem 271, 10697-10703.

16. Matsuzawa Y, Funahashi T \& Nakamura T (1999) Molecular mechanism of metabolic syndrome $\mathrm{X}$ : contribution of adipocytokines adipocyte-derived bioactive substances. Ann N Y Acad Sci 892, 146-154.

17. Yamauchi T, Kamon J, Waki H, et al. (2001) The fat-derived hormone adiponectin reverses insulin resistance associated with both lipoatrophy and obesity. Nat Med 7, 941-946.

18. Johnsson P, Kamal-Eldin A, Lundgren LN \& Aman P (2000) HPLC method for analysis of secoisolariciresinol diglucoside in flaxseeds. J Agric Food Chem 48, 5216-5219.

19. Fritsche J, Angoelal R \& Dachtler M(2002) On-line liquid-chromatography-nuclear magnetic resonance spectroscopy-mass spectrometry coupling for the separation and characterization of secoisolariciresinol diglucoside isomers in flaxseed. J Chromatogr 972, 195-203.

20. Folch J, Lees M \& Sloane Stanley GH (1957) A simple method for the isolation and purification of total lipides from animal tissues. J Biol Chem 226, 497-509.

21. Shoji T, Kobori M, Shinmoto H, Yanagida A, Kanda T \& Tsushida T (2000) Inhibitory effects of apple polyphenols on differentiation of 3T3-L1 cells into adipocytes. Food Sci Technol Res 6, 119-121.

22. Dyck DJ, Heigenhauser GJ \& Bruce CR (2006) The role of adipokines as regulators of skeletal muscle fatty acid metabolism and insulin sensitivity. Acta Physiol (Oxf) 186, 5-16.

23. Armoni M, Kritz N, Harel C, Bar-Yoseph F, Chen H, Quon MJ \& Karnieli E (2003) Peroxisome proliferator-activated receptor-gamma represses GLUT4 promoter activity in primary adipocytes, and rosiglitazone alleviates this effect. J Biol Chem 278, 30614-30623.

24. Hollenberg AN, Susulic VS, Madura JP, Zhang B, Moller DE, Tontonoz P, Sarraf P, Spiegelman BM \& Lowell BB (1997) Functional antagonism between CCAAT/enhancer binding protein-alpha and peroxisome proliferator-activated receptorgamma on the leptin promoter. J Biol Chem 272, 5283-5290. 
25. Iwaki M, Matsuda M, Maeda N, Funahashi T, Matsuzawa Y, Makishima M \& Shimomura I (2003) Induction of adiponectin, a fat-derived antidiabetic and antiatherogenic factor, by nuclear receptors. Diabetes 52, 1655-1663.

26. Kota BP, Huang TH \& Roufogalis BD (2005) An overview on biological mechanisms of PPARs. Pharmacol Res 51, 85-94.

27. Marx N, Duez H, Fruchart JC \& Staels B (2004) Peroxisome proliferator-activated receptors and atherogenesis: regulators of gene expression in vascular cells. Circ Res 94, 1168-1178.

28. Plasad K (2000) Flaxseed: a source of hypercholetsterolemic and antiatherogenic agent. Drug News Perspect 13, 99-104.

29. Mandasescu S, Mocanu V, Dascalita AM, Haliga R, Nestian I, Stitt PA \& Luca V (2005) Flaxseed supplementation in hyperlipidemic patients. Rev Med Chir Soc Med Nat Iasi 109, 502-506.

30. Bhathena SJ, Ali AA, Haudenschild C, et al. (2003) Dietary flaxseed meal is more protective than soy protein concentrate against hypertriglyceridemia and steatosis of liver in an animal model of obesity. J Am Coll Nutr 22, 157-164.

31. Kim HJ, Takahashi M \& Ezaki O (1999) Fish oil feeding decreases mature sterol regulatory element-binding protein 1 (SREBP-1) by down-regulation of SREBP-1c mRNA in mouse liver. A possible mechanism for down-regulation of lipogenic enzyme mRNAs. J Biol Chem 274, 25892-25898.
32. Fujita H, Fujishima H, Koshimura J, Hosoba M, Yoshioka N, Shimotomai T, Morii T, Narita T, Kakei M \& Ito S (2005) Effects of antidiabetic treatment with metformin and insulin on serum and adipose tissue adiponectin levels in $\mathrm{db} / \mathrm{db}$ mice. Endocr J 52, 427-433.

33. Brown NF, Hill JK, Esser V, Kirkland JL, Corkey BE, Foster DW \& McGarry JD (1997) Mouse white adipocytes and 3T3L1 cells display an anomalous pattern of carnitine palmitoyltransferase (CPT) I isoform expression during differentiation. Inter-tissue and inter-species expression of CPT I and CPT II enzymes. Biochem J 327, Pt 1, 225-231.

34. Rosen ED, Walkey CJ, Puigserver P \& Spiegelman BM (2000) Transcriptional regulation of adipogenesis. Genes Dev 14, $1293-1307$.

35. Clavel T, Henderson G, Engst W, Dore J \& Blaut M (2006) Phylogeny of human intestinal bacteria that activate the dietary lignan secoisolariciresinol diglucoside. FEMS Microbiol Ecol 55, 471-478.

36. Lehmann JM, Moore LB, Smith-Oliver TA, Wilkison WO, Willson TM \& Kliewer SA (1995) An antidiabetic thiazolidinedione is a high affinity ligand for peroxisome proliferator-activated receptor gamma (PPAR gamma). J Biol Chem 270, $12953-12956$. 